\title{
Learning Non-Technical Skills from Pedagogical Training: Investigating IGERT Graduate Student Perceptions
}

\section{Catherine G.P. Berdanier, Purdue University, West Lafayette}

Catherine G.P. Berdanier is a Ph.D. Candidate in the School of Engineering Education at Purdue University. She earned her B.S. in Chemistry from The University of South Dakota and her M.S. in Aeronautical and Astronautical Engineering from Purdue University. Her research interests include graduate-level engineering education, including inter- and multidisciplinary graduate education, innovative and novel graduate education experiences, global learning, and preparation of engineering graduate students for future careers. Her dissertation research focuses on studying the writing and argumentation patterns of engineering graduate students.

\section{Dr. Monica Farmer Cox, Purdue University, West Lafayette}

Monica F. Cox, Ph.D., is an Associate Professor in the School of Engineering Education at Purdue University and is the Inaugural Director of the Engineering Leadership Minor. She obtained a B.S. in mathematics from Spelman College, a M.S. in industrial engineering from the University of Alabama, and a Ph.D. in Leadership and Policy Studies from Peabody College of Vanderbilt University. Teaching interests relate to the professional development of graduate engineering students and to leadership, policy, and change in science, technology, engineering, and mathematics education. Primary research projects explore the preparation of engineering doctoral students for careers in academia and industry and the development of engineering education assessment tools. She is a National Science Foundation Faculty Early Career (CAREER) award winner and is a recipient of a Presidential Early Career Award for Scientists and Engineers (PECASE).

\section{Thomas John Wallin, Cornell University}

Thomas Wallin is a doctoral student in Materials Science and Engineering at Cornell University.

Mr. Marc James Murphy

Mrs. Amanda Michelle Lorts Harding, Norfolk State University

Rabia Hussain, Norfolk State University

Mr. Sonny James Penterman, Cornell University

Ms. Vanessa Nicole Peters, Norfolk State University

Vanessa Nicole Peters is a PhD candidate in Materials Science Engineering at Norfolk State University. Her current research involves strong coupling of plasmonic materials and the influence of hyperbolic metamaterials on chemical reactions. As part of a collaborative effort with two other institutions, she also works as part of a team on interdisciplinary research and pedagogy training. This training has been very useful for several of the outreach events and undergraduate training that she has prepared as a graduate student. Vanessa holds a BS in chemistry from Norfolk State University.

Dr. Thejaswi U Tumkur, Rice University

Quincy Leon Williams, Norfolk State University

Dr. Suely M. Black, Norfolk State University

Suely M. Black, Ph.D. is a Professor of Chemistry, and Materials Science and Engineering at Norfolk State University, a Historically Black College and University in Virginia. Suely is driven to developing leadership and management skills in students and junior faculty. She has led the IGERT-MNM program funded by the National Science Foundation for almost five years, focusing on the renovation of graduate education to train doctoral students to become leaders in interdisciplinary areas of materials science, engineering and education. She has served as NSU Faculty Senate President since 2013. Suely teaches undergraduate science and non-science majors, and materials science graduate students. She earned her Ph.D. and M.Ph. in Chemistry from Columbia University, NY, and the B.Eng. in Chemical Engineering and the M.S. in Chemistry from Rio de Janeiro Federal University in Brazil. 


\title{
Learning Non-Technical Skills from Pedagogical Training: Investigating IGERT Graduate Student Perceptions
}

\begin{abstract}
Inter- and multidisciplinary training has been advocated for graduate students as the problems facing science and engineering become increasingly complex. The Integrative Graduate Education Research and Traineeship on Magnetic and Nanostructured Materials (IGERT-MNM) is a collaboration between Purdue University, Cornell University, and Norfolk State University to train interdisciplinary science and engineering doctoral students for future roles as leaders in the materials science and engineering fields. As part of this socialization into future careers, students proceed through a variety of modules. This paper specifically covers student learning in a pedagogy module, which introduces students to best practices in teaching and learning. Graduate student reflections on the development of high-school level student and teacher science and engineering activities were analyzed via thematic coding methods in order to understand skills that students felt they developed as part of this module. Non-technical skills that students developed included communication skills for diverse audiences; the ability to convey technical expertise to non-technical audiences, and the development of virtual teamwork skills.
\end{abstract}

\section{Background and Literature Review}

Many scholars have stressed the importance of graduate education as a method for socializing graduate students into the norms, mentalities, and expectations for their future careers as experts in their field ${ }^{1,2,3-8}$. In academia, the apprenticeship system of graduate school is designed to help students acculturate to the expectations of their advisors, eventually taking on more authentic, useful, and original tasks, including teaching requirements, grant writing, and mentorship of younger students. Several recent studies have begun to analyze the skills needed for practicing engineers--many look at the desired attributes of a bachelor's-level engineer, which have influenced ABET standards, among other curriculum and program development ${ }^{9,10}$. Fewer studies have analyzed the critical knowledge, skills, and attributes of $\mathrm{PhD}$ holding engineers in academia and industry, ${ }^{9,11-13}$ however, it is clear that non-technical skills play a vital role in career success for engineers in any career. Some of these include written and verbal communication skills, and ability to target communication for diverse audiences ${ }^{12,13}$; ability to teach (formally or informally) peers, colleagues, or students technical material ${ }^{3,14}$; and the ability to generate new knowledge in order to advance the technical field ${ }^{2,3,15}$.

Additionally, the 1995 National Academy of Science's report, "Reshaping the Graduate Education of Scientists and Engineers" recognized the failure of current graduate education in the sciences to educate doctoral students to be trained in interdisciplinary settings ${ }^{16}$. This lack of interdisciplinary collaboration and a push for more diverse curriculum has been the focus of many critiques and conversations surrounding graduate education ${ }^{17-20}$. In response to these common findings, the National Science Foundation developed the Integrative Graduate Education and Research Traineeship (IGERT) program. To date, 278 IGERT grants at over 100 universities have been awarded to almost 6,500 trainees "who will pursue careers in research and education, with the interdisciplinary backgrounds, deep knowledge in chosen disciplines, and 
technical, professional, and personal skills to become, in their own careers, leaders and creative agents for change",21.

The IGERT in Magnetic and Nanostructured Materials (IGERT-MNM) grant is one such award given to Norfolk State University (NSU) with collaborators from Cornell University and Purdue University in 2009. IGERT MNM consists of faculty and doctoral students in Materials Science and Engineering from NSU and Cornell as well as Engineering Education faculty and doctoral students from Purdue University. Each year, the IGERT-MNM pedagogy module is led by the Engineering Education collaborators from Purdue. The main objective of the module is to help the IGERT Trainees and associate trainees develop pedagogical expertise in order to integrate pedagogy within their disciplinary areas. To accomplish these objectives trainees were expected to:

1. Understand pedagogical techniques and apply them to science and engineering activity and curriculum design

2. Identify best practices in methods of communicating scientific content to learners

3. Be able to implement backward design principles ${ }^{22}$ to complete a deliverable for use in a classroom setting

4. Gain experience with inter-institution collaborations and communication.

Each of the nine IGERT Trainees from all three institutions participated in this module. Each week Trainees were assigned readings related to best practices in pedagogy, asked to respond with critical questions to the assigned reading, complete reflections on the week's lesson, and gradually work on a larger, final deliverable. Within the eight weeks, the final goal was to design a short hands-on activity for high-school aged students to conduct in a classroom environment which teaches some aspect of magnetic and nanostructured materials research, or another science/engineering topic of the students' choice. Two sets of materials were developed for this activity from each group: One structured toward a teacher and one for the student. The deliverable was designed to reflect the pedagogical content knowledge and curricular knowledge Trainees have gained from the previous weeks of the module.

The weekly reading topics and lessons subject matter included: Backwards Design ${ }^{22}$, communication, formative and summative assessment techniques, learning theory, the How People Learn framework ${ }^{23}$, classroom engagement strategies, and curriculum development. To further the objectives of the module and help share the workload, trainees were grouped into three pairs and one group of three across the campuses, such that no group consisted of students solely from the same university. At the completion of the module, all groups had successfully completed the final deliverable (high school science/engineering activity with student and teacher materials), as well as weekly assignments and reflections from the IGERT students. The IGERT MNM itself represents a community of practice that facilitates situated learning through contextual participation. More specifically, learning the pedagogical frameworks was expressed through the design of lesson plans that are grounded on these frameworks. Because this is a unique model for interdisciplinary graduate level education, and because many graduate students do not have the opportunity to learn theoretically-sound activity or curriculum design, we are interested in studying professional skills that occur as a result of participation in the pedagogy module with the science activity design deliverable.

This interest leads us to our two main research questions: 
1. How do the reflections from current IGERT Trainees show development of skills necessary for socialization into the science and engineering research and teaching community?

2. How can multidisciplinary training (such as through this IGERT pedagogy module) help graduate students develop necessary skills to support their development into a STEM professional?

For clarity through this paper, the graduate students involved in this study are referred to as Trainees, to distinguish them from the "students" for whom they were designing science and engineering activities.

\section{Methods}

Nine IGERT Trainees were involved as participants in the IGERT-MNM pedagogy module. IGERT Trainee reflections were used for formative assessments throughout the module, and at the end of the module, a longer, more in-depth reflection was asked of the students. Trainees were instructed to give their reflections on four different aspects of their experiences within the pedagogy module:

1. Explain how you used backward design in the construction of your activity.

2. Explain how your communication strategies differed between writing for students and writing for teachers?

3. Explain what literature and best practices you used in the design of this learning environment.

4. Reflect on your experiences (difficulties, successes) working with a partner at another university.

Through these four topics, several different aspects of Trainee learning were uncovered, that work toward answering our research questions, above.

The use of reflections to act as evidence for student learning has been widely used before in qualitative methodologies and educational research ${ }^{24}$. In educational settings, it has been noted throughout many disciplines that evaluation and assessment of student learning can be more thoroughly interpreted through these quantitative methods, especially when the learning is regarding students' development in personal or professional aspects ${ }^{25-27}$. The advantage of using student reflections as data is that each student is free to reflect on certain aspects of her or his learning experiences, without being influenced by the answers of other students. In many other studies, student reflections offer great insight into development and secondary learning experiences outside of the primary learning objective: Gaufberg, Batalden, Sands, \& Bell call this a "hidden curriculum" that were unveiled by using emergent coding strategies to interpret medical student reflections on their learning ${ }^{30}$. In this way, other disciplines have also used reflections in order to understand discipline specific learning in a community of practice, such as in medicine, law, or marketing ${ }^{28-32}$. As a disadvantage, the quality of data from reflections is dependent upon the quality and effort that the students put into their reflection; however; even through this small sample size of nine students, we achieved a wealth of qualitative data through these responses.

Reflections were coded by three of the IGERT Trainees using content analysis methods to establish emergent themes, as described by Creswell $^{24}$. Participant numbers were allocated to 
each of the Trainees' reflections in order to protect identity: Any quotations that directly mentioned another Trainee were amended via brackets in order to protect confidentiality. The reflections were coded individually by the first three authors of the paper. The units of analyses were either sentences or small paragraphs that conveyed a single main idea or example. After coding individually, the the emergent themes were discussed as a group in order to reach consensus on grouping of quotations into three primary themes, which incorporated some smaller secondary themes as displayed in Figure 1. After the data was analyzed, the written findings were transferred back to the remainder of the IGERT Trainees for member checks in order to validate findings and obtain any clarifications and edits. Representative quotations for the results section were chosen to best represent the theme while presenting views from each of the Trainees, and are correlated with participant number.

\begin{tabular}{|c|c|c|c|}
\hline $\begin{array}{l}\text { Primary } \\
\text { Themes }\end{array}$ & $\begin{array}{l}\text { Primary Theme } \\
\text { Definition }\end{array}$ & Secondary Themes & Secondary Theme Definition \\
\hline \multirow{4}{*}{$\begin{array}{l}\text { Communication } \\
\text { with Diverse } \\
\text { Audiences }\end{array}$} & \multirow{4}{*}{$\begin{array}{l}\text { Conscious scoping of } \\
\text { language and topics } \\
\text { to suit prior } \\
\text { knowledge of } \\
\text { audience }\end{array}$} & Identify areas of interest & $\begin{array}{l}\text { Scope activities and topics to those that are } \\
\text { relevant and interesting to various learners }\end{array}$ \\
\hline & & Diagnose prior knowledge & $\begin{array}{l}\text { Figure out prior knowledge or expertise of } \\
\text { learners or teachers }\end{array}$ \\
\hline & & Identify Familiarity & $\begin{array}{l}\text { Figure out familiarity of audience with } \\
\text { phenomena and examples }\end{array}$ \\
\hline & & $\begin{array}{l}\text { Understand one's expert } \\
\text { positionality }\end{array}$ & $\begin{array}{l}\text { Consciously break down expert knowledge } \\
\text { for communication, may consider diversity } \\
\text { of audience (socioeconomic status, grade } \\
\text { level, prior knowledge, etc.) }\end{array}$ \\
\hline \multirow{4}{*}{$\begin{array}{l}\text { Use of } \\
\text { Technical } \\
\text { Expertise in } \\
\text { Translating } \\
\text { Knowledge }\end{array}$} & \multirow{4}{*}{$\begin{array}{l}\text { Use scientific } \\
\text { principles and } \\
\text { educational principles } \\
\text { as tools to design } \\
\text { educational activity }\end{array}$} & $\begin{array}{l}\text { Knowing one's own } \\
\text { expertise }\end{array}$ & $\begin{array}{l}\text { Delineate the important basic concepts } \\
\text { embedded in complex science and } \\
\text { engineering principles }\end{array}$ \\
\hline & & $\begin{array}{l}\text { Develop learning } \\
\text { objectives }\end{array}$ & $\begin{array}{l}\text { Use basic concepts to define relevant and } \\
\text { appropriate learning objectives }\end{array}$ \\
\hline & & Scoping of assessments & $\begin{array}{l}\text { Develop formative and summative } \\
\text { assessments aligned with learning objectives } \\
\text { and content }\end{array}$ \\
\hline & & $\begin{array}{l}\text { Developing learning } \\
\text { environments }\end{array}$ & $\begin{array}{l}\text { Make decisions that promote authentic and } \\
\text { inquiry-based learning }\end{array}$ \\
\hline \multirow{4}{*}{$\begin{array}{l}\text { Development of } \\
\text { Teamwork and } \\
\text { Interpersonal } \\
\text { Skills }\end{array}$} & & Leadership & Styles of leadership within various teams \\
\hline & & Teamwork Skills & $\begin{array}{l}\text { Trust, honesty, and other interpersonal skills } \\
\text { that enhance team productivity }\end{array}$ \\
\hline & & Strategies for Success & $\begin{array}{l}\text { Any mention of strategies that were used to } \\
\text { mitigate scheduling difficulties, working at } \\
\text { different institutions, etc. }\end{array}$ \\
\hline & & Communication & $\begin{array}{l}\text { Methods for optimal communication as } \\
\text { decided by teams (phone, email, etc.) }\end{array}$ \\
\hline
\end{tabular}

Figure 1: Primary and secondary coding schema and definitions

\section{Results}

The themes found from the above coding scheme can be divided into the three primary categories to present results and interpretation: Communication with Diverse Audiences; Use of 
Technical Expertise in Translating Knowledge; and Development of Teamwork and Interpersonal Skills. The protocol for the reflective essays did not ask specifically about these aspects of development; but about the use of the content presented in class. The outcomes of the reflective essays on these tenets of the pedagogy module reveal that development occurred through the module in different, broader areas of professional development. Each of these aspects will be covered in depth through this section. These main categories also help us to answer our two research questions regarding how Ph.D. students are socialized to work at the standards necessary for experts in academia, and also how students learn to transform their knowledge to different audiences and environments. Although the quotations may be long, the research team has determined that the entirety of the quote is necessary to establish participant voice and context; however, certain important elements of the longer quotations will be in boldface font in order to emphasize the areas of importance which influenced the coding schema. Each participant is represented in at least one quotation.

\section{Communication with Diverse Audiences}

Communication with diverse audiences is a skill that has been listed in literature as highly lacking for Ph.D. level engineers, and also cited as an attribute for success necessary for Ph.D. students ${ }^{18,33-36}$. Through the analysis of the reflective essays, many Trainees reflected on their experiences creating both student materials and teacher materials that accurately present complex scientific and engineering concepts in ways that can be easily understood. Many Trainees discussed the difficulty in assessing prior knowledge of both students and teachers, especially since many materials science and engineering concepts bridge several disciplines (specifically, math, science, and physics, which, in high schools are usually not integrated tightly.)

"Our topic is more engineering than science based. The mechanical properties of materials might come up in a conventional science curriculum, but the nuances of composite materials surely do not. As such, we really had to treat the teacher and the student as uninformed audiences. For this reason, our communications between the two groups were very similar. The main difference was that we included more information for the teachers [...] In reflection, we may have assumed too much expertise on the part of the teachers and should have included more references and reading." (Participant 8)

"Designing the content and activities that are tailored towards an audience that has a limited background in nanotechnology was one of the more challenging aspects of creating this lesson plan. Because teachers are expected to have a higher capacity to learn and understand concepts at the most basic level, writing the content for the teacher's packet was far more trivial than the student's packet. [...]The most significant challenge with writing the student packet was presenting content that provided an appropriate balance of depth and simplicity. Unfortunately, much of our written content was under various assumptions about the students' background and prior knowledge in various scientific disciplines. "(Participant 5)

Other Trainees discussed difficulties they had in writing for these two different audiences, often noting that writing for students was much harder than writing for teachers, because it was 
assumed that high school science teachers have a level of experience and technical expertise, even if the subject (of nanotechnology, for example) is fairly new to them.

"This part of the activity [communication strategies for different audiences] seemed more difficult for some of us in the group. When I wrote for students, I used language and explanations that were easy for them to understand (at their age and scientific education level). I tried to refer to things that would both interest high school students and that they would be most familiar with. For example, I described one of the most important applications of nanotechnology (faster, more efficient, and higher capacity electronic storage and processing chips) as improving computers and cell phones, which teenagers likely use on a daily basis." (Participant 1)

"The communication strategies used for the student version of the lesson plan differed from those used in the teacher's version. The teacher's version provided more detail related to the chemistry and physics concepts that underline the student lesson plan. In this way, the teacher's version serves to help in answering various questions that students might have along the way. These concepts were not addressed in detail for the student version in order to avoid confusion while focusing more directly on the stated learning objectives. The teacher's version of the material also proceeds under the assumption of some previous background in physical and environmental science, and avoids any unnecessary motivation sections or self-evaluation exercises. "(Participant 6)

"We believe that many teachers have sufficient knowledge of content (teachers are required to know content for certification and employment), however, we felt that pedagogical instruction would be necessary for a hybrid reading/science course (many science teachers may not remember best practices for enhancing students reading skills). We included several examples of tips and note-taking strategies teachers could include in the lesson and we instructed teachers on what to do if they could not find appropriate reading materials." (Participant 3 )

The IGERT Trainees also realized that "prior knowledge" of their intended audience might differ from their own past experience, reflecting that issues such as geographical location and socioeconomic status might change the perceptions of students and teachers in a learning environment. Students and teachers from disadvantaged school districts may not have access to state-of-the-art tools and materials, or even access to computers. Students in different geographic locations might not have the same prior knowledge of naturally-occurring snow outside to think about phases of water! The data in the reflections show that the IGERT Trainees began to understand that in order to communicate effectively with their student and teacher audiences, they needed to overcome their own prior knowledge and assumptions.

"Upon the completion of the lesson plan, I realized the deep-seeded complexity associated with modifying content that's catered towards the collective needs and capabilities of the students, which are heavily dependent on geographical and socioeconomic variables. " (Participant 5) 
The IGERT Trainees used a variety of techniques in order to overcome some of these difficulties in anticipating the needs and prior knowledge of the students and teachers for which the activities were being designed. Some ways to better predict the needs of the audience to aid communication were through the use of the K-12 Next Generation Science Standards ${ }^{37}$, which show "grade bands" at which levels topics might be introduced to high school students. Other Trainees noted asking friends who have experience as high school science teachers which concepts their students have trouble with, in order to better gauge the needs of current high school students.

Some techniques for communication with the high school student users specifically involved activities and communication within the activity itself. One Trainee noted the effort to make the reading in the student packet "not boring" in order to retain interest for future student users. Other Trainees noted that they specifically mentioned in the materials the relation of the concepts presented to real-world topics that high school students find interesting, like technology. Most Trainees used a variety of pedagogical engagement strategies to keep students interested, through dividing the lesson into parts, employing team learning strategies, and using visual demonstration and hands-on activities to promote problem-based and challenge-based learning environments.

"When we were writing for the students, I think that we tried our best to help students not be bored by the reading ... after all, if they are bored with the reading, they'll likely be "bored" with the science concepts as well." (Participant 2)

"Particularly, How People Learn made us more aware of the strategies we were employing. I know I intentionally attempted to incorporate multiple "centers of learning" in our activity. The other best practice that we incorporated was problembased learning. We wanted students to have the freedom to direct their own learning by giving them a choice of materials to incorporate into the mechanical testing and composite engineering. We incorporated a "challenge" into the lesson plan to help motivate students and encourage active knowledge transfer. "(Participant 8)

\section{Use of Technical Expertise in Translating Knowledge}

The doctoral-level IGERT Trainees overall noted that they were able to use their own expertise and past experience when designing the activities and the materials for the students and the teachers. Some Trainees noted that they applied the pedagogy skills that they had learned in previous years as well as the material covered this year in order to best design the learning environment for the high school students and present the student and teacher materials.

Most Trainees reported relying heavily on their own expertise as doctoral students when planning their activities and selecting topics, learning objectives, and curricular priorities. In terms of topic selection, Trainees discussed selecting "non-traditional" topics that are important for pre-college students to understand that are related to fundamentals in a discipline.

"I was more interested in finding activities that required little or no lecture time and [my partner] was interested in introducing concepts that are not emphasized in a standard 
HS lesson. We decided to use both ideas by using the student materials to describe a nontraditional topic in chemistry (material's purity and purification methods) and the teacher's materials to describe a guided analysis activity." (Participant 3)

"With cutting edge technologies based on nanotechnology becoming the standard, it's only a matter of time before it's systematically incorporated into our national school curriculum. We therefore chose nanotechnology from a more fundamental perspective as our central topic for our designed lesson plan."(Participant 5)

"We first established learning objectives that closely align with concepts what we believe are essential for understanding nanotechnology. Additional criteria was that our learning objectives had to be feasible to accomplish within a small time frame, as well as appropriate for the learning capabilities of students at the high school level." (Participant 5)

Furthermore, Trainees developed the skills of combining their past pedagogy experience with the presentation of the technical content, noting that the use of frameworks such as backward design helped to "eliminate extraneous information" when presenting complex technical information to students. By planning to employ frameworks such as the National Research Council's How People Learn framework (which proposes designing learning environments be learner-centered, knowledge-centered, assessment-centered, and community-centered) ${ }^{23}$, the IGERT Trainees were pressed to create different activities which applied to each of these areas, thereby creating more in-depth, relevant, and engaging activities for students. The use of the learning frameworks in a technical context also helped the IGERT doctoral students to take their deep knowledge of an area and learn to break down complex topics into discrete and realistic learning objectives that can be accomplished in a short period of time. This took much iteration of topic and learning objective selection, complicated by different student views on curricular priorities of the same topic.

"We attempted to implement not only "Backwards Design", but also "How People Learn" by including multiple forms of learning environments, such as community-based learning [small group discussions of the information presented by the pre-activity reading and also what the teacher had provided (knowledge-based environment)], learner-centered environment (pre-test), and assessment-centered learning environment (post-test, student reflections turned in at the end of the lesson)." (Participant 1)

"We used the PAR (Preparation, Assistance, Reflection) lesson framework for our lesson. It is primarily a constructivist type of framework, but many of its principles correlate well with the How People Learn (HPL) Framework. We ensured every aspect of the lesson had a preparation, assistance, and knowledge phase." (Participant 3)

"As experts familiar with the topic, it is easy for us to inundate the students with too much information and assume prior knowledge. By remembering our initial learning objectives, we narrowed our focus to the more attainable outcomes. Additionally when designing the assessment for the activity, we were able to refer back to these learning 
objectives and develop questions that truly assess whether knowledge transfer occurred." (Participant 8)

Overall, these reflections showed that the IGERT Trainees learned to harness their own technical expertise in order to transform it to different environments and for different audiences. Because the goal for the final deliverable was to apply pedagogy knowledge from previous years in the IGERT module with the goal of designing an activity around their technical expertise, Trainees were able to comfortably design the materials to meet the needs of the two distinct groups of people for which they were designing materials.

Ultimately, learning to translate knowledge to various audiences is a professional skill that can be transferred to many different environments, even if they do not specifically involve activity design for 9-12 grade students. For the IGERT Trainees planning future careers as faculty, scoping lesson plans and learning environments for introductory physics, chemistry, and engineering courses operate with most of the same prior assumptions about learners as do advanced high school students, since professors are not able to assume that all incoming firstyear students have taken advanced science and math classes. For faculty teaching at other levels, learning to apply pedagogical principles in an authentic situation will ease the burden of learning to design curricula as professors. For IGERT Trainees pursuing industry careers, education at some level may be a part of working with teams or onboarding younger or less educated coworkers, and so working to understand strong pedagogical principles is also important. Students learned the value of both formative and summative assessments, as well as learning different pedagogies of engagement that will appeal to the various learning styles of their future students. Students especially noted using different strategies within their activities to gauge student learning of technical concepts (not just summative tests):

"We also incorporated opportunities for frequent feedback by the students in the form of anonymous written statements. The purpose of the feedback was to not only assess what concepts students understand, and what concepts they're struggling with, but also to gauge their overall interest and investment in the activities. "(Participant 5)

"Developing assessments for these learning objectives and especially the enduring understandings, we started to realize that we had a lot of content that was not tightly linked or demonstrated in our activity. Additionally, given the age and assumed prior knowledge of our learners, we struggled to negotiate concepts that we know are important as scientists with what the students could learn in a 90 minute lesson. The way that we mitigated this issue was to iterate on our learning objectives, assessment and content until they were properly aligned in the form of a well-developed activity."(Participant 2)

Since many students developed experience in developing alternative, more student-centered assessments for their learners, it is likely that they will consider using these teaching and assessment techniques in future experiences as instructors across a variety of circumstances.

Development of Teamwork and Interpersonal Skills 
Lastly, the Trainee reflections noted strong improvement in developing interpersonal and working relationships with their peers while designing the activity. As it was planned, teams of two Trainees from different universities would be paired, with one taking leadership on the student materials and the second student taking leadership on the teacher materials. There was one team of three that split these tasks evenly. The groups were left to their own devices in order to work out a communication system and accomplish the deliverables due for the next week, thereby developing professional skills in teamwork, communication, dealing with time management and competing priorities, and working via distance--all skills that are relevant to careers in industry or in academia.

Trainees specifically noted the need in these groups for leadership. Without one person taking a leadership role, decisions were sometimes very difficult or were delayed.

"In many ways, our group failed to name a leader, which complicated the entire process. Each of us offered thoughts, ideas, and suggestions, but we had a difficult time deciding on any one thing. In the future, working with people who are similarly laid-back, I would recommend early on deciding one person to lead the project and encourage making a pro/con list of each person's ideas to hopefully facilitate deciding on the best strategy for each aspect of the project." (Participant 1)

"...[O]ur personalities were similarly passive, and no one truly took command of this project. Moreover, I think that the initial disconnect adversely affected the initial stages, which resulted in our group prematurely picking a topic." (Participant 5)

Other Trainees noted the importance of honesty, trust, and negotiation in working in teams where both partners have other roles as students, researchers, and family members. Most groups mentioned that finding times to meet as a group was rather difficult, but was overcome by active communication through email, or virtual communications such as Skype or Google Hangouts.

"Working with group members outside of Cornell provided a valuable experience for me. One of the major hurdles that I immediately noticed when working in long-distance collaborations was finding suitable times to interface with the other group members. "(Participant 5)

"It was hard! We were three members and all of us had time conflicts sometimes. We managed to communicate via google hangout, emails and texting and I guess we survived!" (Participant 4)

"It was of utmost importance that we communicate with each other clearly in terms of allocating responsibilities upfront, and also being honest about time commitments throughout the module."(Participant 2)

"The bigger issue was that we had other priorities, so at times this assignment was placed on the back burner. In those situations, one partner would step up and share their work with the other partner. The other partner would review and add as needed. When issues arose, a simple instant message could be sent to address the situation. It 
seemed that there was a need to be flexible with deadlines and allow others to work on their own timelines, but it was not an insurmountable barrier. "(Participant 8)

In spite of these competing priorities, some groups noted advantages that came from working with Trainees from different institutions with differing schedules. One group noted that the negotiation of both student materials meant that both students in the team got experience working with both sets of materials, which was good in order to practice communicating with different audiences.

"Although we started out splitting up the activity by teacher materials and student materials, we quickly realized that because of life circumstances, certain weeks were going to be heavy on one person or another. The important thing about this was to be transparent, not overcommit, and not just "disappear" when one of us couldn't manage our responsibilities; rather, we worked together and negotiated: "I'll get the assignments done for this week and complete the update slide if you can take next week."-In this way, we accomplished the whole task, and as a benefit, we also got the opportunity to work on both the teacher materials and the student materials."(Participant 2)

"By working with someone who was very orderly and time oriented allowed me to see the importance of the task and kept me on my toes.[...]The experience was beneficial to me because it allowed me to see others work ethic and allowed me to gain knowledge about a field I was not very familiar with. I was able to see how the alignment of lesson plans and activities can be very time consuming and the use of frameworks allow for the writer to systematically formulate a creative, and well put together lesson." (Participant 9)

The Trainees came to several conclusions about strategies to best manage group work in a professional setting in order to meet timeline deliverables and expectations. First, they noted the importance of responsive communication in whatever medium the team decides works best. Second, the Trainees realized that differing perspectives, even if they require discussion, often lead to achieving more creative ideas. Thirdly, students noted that transparency in the division of labor and competing commitments led to trust in their partners and led to a better working experience on this project.

"Communication between my partner and I consisted of multiple emails, back and forth, at all times of the day or night, based on our schedule. At one time we did meet by video, using Skype, when hashing out our ideas and talk over our roles in the completion of work."(Participant 9)

"Communication was not a problem since we used instant messaging, and we were both very responsive." (Participant 7)

"The experience was challenging. We had to trust each other quite a bit since we were unable to talk to each other on a regular basis. I preferred email communication because it was more flexible than planning videoconferencing dates. "(Participant 3) 
Because of the arrangement of the groups, it was intended that Trainees develop their own strategies for accomplishing work at different locations--a skill that is becoming more necessary as industries often employ virtual teaming strategies or offer work-from-home solutions. However, the Trainee responses in their negotiation and teamwork strategies surpassed the expectations, revealing some creative solutions to the teamwork and resulting in stronger working relationships between students at various universities in the IGERT collaboration.

\section{Discussion}

The two research questions that we sought to answer through this study of materials science engineering doctoral students as they completed a pedagogy module.

1. How do the reflections from current IGERT Trainees show development of skills necessary for socialization into the science and engineering research and teaching community?

Our findings indicate that Trainees developed a variety of skills through this IGERT module that are socializing them into the expectations for their future careers as engineering professionals in academia and industry. From literature, authentic activities are the basis for situated cognition, and this is entirely demonstrated as students applied their technical knowledge to a pedagogy activity in order to create legitimate activities for high school students and teachers $38-40$. This is authentic in the fact that the prior knowledge of learners is not discussed in a theoretical sense, but must actually be able to be applied in a classroom setting where students only have a limited background in practical science and math.

Additionally, The IGERT Trainees began to understand what is required to practice in the educational sphere of science and engineering and technical communication. By applying the learning theories to the subject of their expertise, they showed that they adopted the pedagogical principles of backward design, use of learning frameworks, and pedagogies of engagement and assessment strategies--all considerations that are required by STEM education and STEM curriculum design professionals. Additionally, some educational researchers have applied the analogy of designing learning environments as being very similar to the design process that engineers are trained to use ${ }^{22,41-43}$.

Through this experience, Trainees also became more understanding of their expertise in science and engineering, specifically in complex topics such as considering the size and scale of nanoparticles. By determining ways to best teach concepts to inexperienced learners, and potentially inexperienced teachers with little background in cutting-edge technical research, students showed that they truly understood the topic enough to teach it authentically in a variety of methods.

\section{How can multidisciplinary training (such as through this IGERT pedagogy module) help} students develop necessary skills to support their development into a STEM professional?

Although the IGERT is intended to enhance the preparation of science and engineering graduate students to perform interdisciplinary research, many non-technical skills are part of the necessary attributes for student success in future careers. We argue that the non-technical skills that 
students reflected on developing (communication skills for diverse audiences, harnessing technical knowledge in order to convey it to non-technical audiences; and team work with partners at different universities) are crucial by-products to the implementation of multidisciplinary and interdisciplinary curriculum within the IGERT-MNM program. These skills are cited in research as being a necessary part of technical science and engineering jobs, whether they be in academia or in an industry workplace setting. As careers become more highly interdisciplinary, the marriage of technical expertise and these non-technical skills will become more prized for engineering and science Ph.D.-level engineers.

Surprises that were noted within the responses were the Trainees learning that resulted by diversifying the partnerships through which the projects were accomplished. By pairing Trainees randomly with partners from different universities, they were forced to establish their own working culture and team management systems, noting often that they learned from each other's working styles and value team leadership in virtual working situations.

\section{Conclusion}

The IGERT-MNM project is uniquely qualified to target and address common problems in the traditional graduate education program for science and engineering. The pedagogy module of 2014 challenged the Trainees to work in teams to develop a science and engineering for high school students and teachers. Though this was the first time this exact modular course was attempted, the trainee reflections clearly demonstrate that this experience effectively prepares the trainees "to contribute to a world-class, broadly inclusive, and globally engaged science and engineering workforce" ${ }^{21}$. Three of the four activities were presented at the National Educator's Conference in Seattle in 2014, a conference aimed at high school, junior college, and university materials science and engineering educators.

The reflections show the Trainees struggled with and utilized pedagogical strategies to overcome the difficulties with communicating science and engineering topics to diverse audiences-high school students and teachers. As part of this necessity to transfer their own expertise to a potential uninformed audience, the trainees identified and employed some best practices in pedagogy (e.g.: How People Learn ${ }^{23}$ and Backwards Design ${ }^{22}$ frameworks) from their modular IGERT coursework. Additionally, the trainees noted in their reflections that requirements of inter-institutional and inter-disciplinary collaborations developed the necessary interpersonal and teamwork skills. The community of practice of this IGERT-MNM pedagogy module reflects the diversity and inclusive nature of the broader scientific and engineering community. These findings indicate that many other skills that are necessary for doctoral science and engineering students' socialization into the professional field can come as a result of multi- and interdisciplinary training such as IGERT.

Acknowledgements: This material is based in part upon work supported by the National Science Foundation under Grant Number 0966188. Any opinions, findings, and conclusions or recommendations expressed in this material are those of the author(s) and do not necessarily reflect the views of the National Science Foundation. 


\section{References}

1. Nerad, M. (2004). The PhD in the US: Criticisms, Facts, and Remedies. Higher Education Policy, 17(2), 183-199.

2. Wendler, C., Bridgeman, B., Cline, F., Millett, C., Rock, J., Bell, N., \& McAllister, P. (2010). The Path Forward: The Future of Graduate Education in the United States. Educational Testing ... (p. 64). Princeton, NJ.

3. Austin, A. E. (2002). Preparing the Next Generation of Faculty: Graduate School as Socialization to the Academic Career. J. Higher Educ. 73, 94-122.

4. Gardner, S. K. (2008). Fitting the Mold of Graduate School: A Qualitative Study of Socialization in Doctoral Education. Innov. High. Educ. 33, 125-138.

5. $\quad$ Braxton, J. M. \& Baird, L. L. (2001). Preparation for professional self-regulation. Sci. Eng. Ethics 7, 593610.

6. Bieber, J. P. \& Worley, L. K. (2006). Conceptualizing the Academic Life: Graduate Students' Perspectives. J. Higher Educ. 77, 1009-1035.

7. Anderson, M. S. \& Swazey, J. P. (1998). Reflections on the Graduate Student Experience: An Overview. New Dir. High. Educ. 1998, 3-13.

8. Anderson, M. S. \& Louis, K. S. (1994). The graduate student experience and subscription to the norms of science. Res. High. Educ. 35, 273-299.

9. American Society for Engineering Education. (2013). Transforming Undergraduate Education in Engineering. 1-50. 〈http://www.asee.org/TUEE_PhaseI_WorkshopReport.pdf>

10. ABET. (2013). Criteria for accrediting engineering programs: Effective for reviews during the 2014-2015 accreditation cycle. 〈http://www.abet.org>

11. Nguyen, D. (1998). The essential skills and attributes of an engineer: a comparative study of academics, industry personnel and engineering students. Glob. J. Eng. Educ. 2,

12. Nair, C. \& Patil, A. (2008). Industry vs universities: Re-engineering graduate skills-a case study. Qual. Stand. High. Educ. Mak. a Differ. 1-7 /

$<$ http://works.bepress.com/cgi/viewcontent.cgi?article=1014\&context=hamish_coates\#page=85>

13. Akay, A. (2008).A renaissance in engineering PhD education. Eur. J. Eng. Educ. 33, 403-413.

14. Austin, A. E., Connolly, M. R. \& Colbeck, C. L. (2008). Strategies for preparing integrated faculty: The center for the integration of research, teaching, and learning. New Dir. Teach. Learn. 113, 69-82.

15. Neumann, R. (2005). Doctoral Differences: Professional doctorates and PhDs compared. J. High. Educ. Policy Manag. 27, 173-188.

16. Committee on Science, Engineering, and P. P. (1995). Reshaping the graduate education of scientists and engineers. Academic medicine : journal of the Association of American Medical Colleges (Vol. 70, pp. 1206). Washington D.C.: National Academies Press.

17. Schillebeeckx, M., Maricque, B., \& Lewis, C. (2013). The missing piece to changing the university culture. Nature Biotechnology, 31(10), 938-41.

18. Tranquillo, J. (2013) The T-shaped Engineer: Connecting the STEM to the TOP. in 120th ASEE Annu. Conf. Expo. 1-21.

19. Meier, R. L., Williams, M. R., \& Humphreys, M. A. (2000). Refocusing Our Efforts: Assessing NonTechnical Competency Gaps. Journal of Engineering Education, (9752083), 377-385.

20. Vest, C. (2008). Context and challenge for twenty-first century engineering education. Journal of Engineering Education, (July), 235-240.

21. The National Science Foundation. (2013). IGERT Mission and History. http://www.igert.org/public/about/history-and-mission

22. Wiggins, G. \& McTighe, J. (1998). Understanding by design. Design 6066, 1-16.

23. National Research Council. (2004). How people learn. Washington DC, National Academy Press. 〈http://www.csun.edu/ SB4310/How People Learn.pdf>

24. Creswell, J. W. (2012). Educational Research: Planning, Conducting, and Evaluating Quantitative and Qualitative Research (Fourth ed., p. 650). Boston, MA: Pearson Education, Inc.

25. Peltier, J. W. (2005). The Reflective Learning Continuum: Reflecting on Reflection. Journal of Marketing Education, 27(3), 250-263. 
26. Richardson, G. \& Maltby, H. (1995). Reflection-on-practice: Enhancing student learning. J. Adv. Nurs. 22, $235-42$.

27. Zimmerman, B. J. (2008). Investigating Self-Regulation and Motivation: Historical Background, Methodological Developments, and Future Prospects. Am. Educ. Res. J. 45, 166-183.

28. Mohr, A. J. \& Rodgers, K. J. (1973). Legal Education: Some Student Reflection. J. Legal Educ. 25, 403426.

29. George-Palilonis, J. \& Filak, V. (2009). Blended Learning in the Visual Communications Classroom: Student Reflections on a Multimedia Course. Electron. J. e-Learning 7, 247-256.

30. Gaufberg, E. H., Batalden, M., Sands, R. \& Bell, S. K. (2010).The hidden curriculum: what can we learn from third-year medical student narrative reflections? Acad. Med. 85, 1709-16.

31. Simons, L. \& Cleary, B. (2005). The influence of service learning on students' personal and social development. Coll. Teach. 54, 307-319.

32. Storch, N. (2005). Collaborative writing: Product, process, and students' reflections. J. Second Lang. Writ. 14, 153-173.

33. Morse, W. C., Nielsen-Pincus, M., Force, J. E. \& Wulfhorst, J. (2007). Bridges and Barriers to Developing and Conducting Interdisciplinary Graduate-Student Team Research. Ecol. Soc. 12, 1-8.

34. Dannels, D. (2002). Communication Across the Curriculum and in the Disciplines: Speaking in Engineering. Commun. Educ. 51, 254-268.

35. Evans, D. L., Beakley, G. C., Crouch, P. E. \& Yamaguchi, G. T. (1993). Attributes of Engineering Graduates and Their Impact on Curriculum Design. J. Eng. Educ. 82, 203-211.

36. Akay, A. (2008). A renaissance in engineering PhD education. Eur. J. Eng. Educ. 37-41.

37. The Next Generation Science Standards | Next Generation Science Standards. http://www.nextgenscience.org/next-generation-science-standards

38. Brown, J. S., Collins, A. \& Duguid, P. (1989). Situated Cognition and the Culture of Learning. Educ. Res. 18, 32-42.

39. Bransford, Sherwood, Hasselbring, Kinzer \& Williams. (1990). Anchored Instruction and its Relationship to Situated Cognition. Educ. Res. 19, 2-10.

40. Arbaugh, J. B., Cleveland-Innes, M., Diaz, S. R., Garrison, D. R., Ice, P., Richardson, J. C., \& Swan, K. P. (2008). Developing a community of inquiry instrument: Testing a measure of the Community of Inquiry framework using a multi-institutional sample. The Internet and Higher Education, 11(3-4), 133-136.

41. Bannan-Ritland, B. (2003). The role of design in research: The integrative learning design framework. Educ. Res. 32, 21-24.

42. Streveler, R. A., Smith, K. A., \& Pilotte, M. (2012). Aligning course content, assessment, and delivery: Creating a context for outcome-based education. In Outcome-based science, technology, engineering, and mathematics education: Innovative Practices (pp. 1-26).

43. Design Based Research Collective. (2003). Design-Based Research: An Emerging Paradigm for Educational Inquiry. Educ. Res. 32, 5-8. 